\title{
Operative risk of correction of atrioventricular septal defects
}

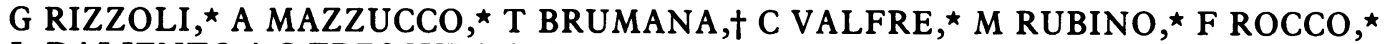 \\ L DALIENTO, $†$ C FRESCURA, $\ddagger$ V GALLUCCI* \\ From the Departments of ${ }^{\star}$ Cardiac Surgery, + Cardiology, and $\ddagger$ Paediatrics, University of Padua, Padua, Italy
}

SUMmaRY Between 1 January 1975 and 31 December 1982, 111 patients with atrioventricular septal defect underwent surgical repair. Of these, 43 had the complete, 11 the intermediate, and 57 the partial form. The postoperative mortality rate was $37 \%, 9 \%$, and $6 \%$ respectively. To determine which factors were independently responsible for the operative risk multivariate analysis of the surgical mortality was applied simultaneously to all three forms of the malformation. The form of defect, although strongly influencing the natural history and clinical presentation, was not by itself an operative risk factor. The risk was related primarily to failure to obtain a well functioning atrioventricular valve, to the presence of left ventricular dominance, to the degree of pulmonary vascular resistance, and, finally, to the technique of reconstructing a two leaflet left atrioventricular valve. The small size of the patient was also a significant incremental risk factor, but if the other factors were not unfavourable good results could be achieved in small infants with mortality rates $<10 \%$.

Multivariate analysis showed that severe postoperative left atrioventricular valve malfunction was related to the technique used to reconstruct a "normal" two leaflet left atrioventricular valve. These findings support the policy of reconstructing the left atrioventricular valve as a three leaflet valve. Nevertheless, the implicit beneficial effect of this technique has not as yet proved to be statistically significant.

An atrioventricular septal defect may result in a broad spectrum of malformations that are traditionally grouped as partial, intermediate, and complete forms of the atrioventricular canal. ${ }^{1}$ The complete form is identified by the presence of a common atrioventricular orifice straddling the scalloped ventricular septum. In the partial form the anterior and posterior leaflets of the common valve are fused together and firmly attached to the deficient crest of the ventricular septum resulting in two functionally separate atrioventricular orifices. The intermediate form includes cases without a distinct cleft of the septal leaflet of the left atrioventricular valve (type 1 of Bharati et $a l^{2}$ ) and also cases, similar to a number of those we have operated on, in which the bridging leaflets are connected by valve tissue that is not completely adherent to the

Requests for reprints to Dr Giulio Rizzoli, Cardiochirurgia, Ospedale Civile, Via Giustiniani 2, 35100 Padova, Italy.

Accepted for publication 5 April 1984 septal crest, thus creating one or more ventricular septal defects (type 2 and 3 of Bharati et $a l^{2}$ ).

The clinical presentation and the natural history of the disease vary greatly according to the severity of the anatomical and haemodynamic involvement. ${ }^{3}$ Patients with a common atrioventricular orifice, a large ventricular septal defect, or left valvar incompetence tend to develop severe heart failure and pulmonary vascular obstructive changes in the first months of life ${ }^{4}$; only a minority survives to childhood. ${ }^{5}$ For these reasons we undertake primary repair at any age, irrespective of the patient's condition, in an attempt to modify favourably the natural history of the disease. Nevertheless, several unfavourable factors are responsible for the still high surgical mortality ${ }^{6}$ in young patients.

We report our recent experience in the surgical treatment of atrioventricular septal defect and identify some statistically significant incremental risk factors which jeopardise the success of total repair. 


\section{Patients and methods}

One hundred and eleven patients underwent surgical repair of an atrioventricular septal defect at the cardiac surgery department of the University of Padua between 1 January 1975 and 31 December 1982. Of these, 43 had the complete form of atrioventricular septal defect (26 Rastelli type C, 15 type A, and two type B), 11 the intermediate form, and 57 the partial form. Forty six patients had Down's syndrome, and two had previously undergone pulmonary artery banding. The left atrioventricular valve was severely incompetent in $65 \%$ of patients with the complete form, $64 \%$ of those with the intermediate form, and $50 \%$ of those with the partial form of atrioventricular septal defect. In all but five with the complete form the ventricular septal defect was large and unrestrictive, whereas in those with the intermediate form it was always small and restrictive.

Six patients had left ventricular and four right ventricular dominance. Thirty had associated major anomalies (Table 1).

Median age at the time of operation was 72 (range 1-744) months, and the corresponding median weight was $16.6 \mathrm{~kg}$. Patients with the partial form were significantly older (median age 137 months) than those with the intermediate (median age 45 months) and complete forms (median age 12 months) $(p=0.001)$. Thirty six patients were under 2 years of age. All had the complete or intermediate form, except for three patients aged 16,19 , and 21 months, who had a partial defect. Of these 36 patients, 19 were $<1$ year old and four $<6$ months $(5.5,1.3,5.1,5.7$ months).

OPERATIVE TECHNIQUE

Repair was carried out using the standard cardiopul-

Table 1 Mortality rate of patients with atrioventricular septal defects (1975-82) in relation to major associated lesions

\begin{tabular}{|c|c|c|c|}
\hline $\begin{array}{l}\text { Associated } \\
\text { lesions }\end{array}$ & $\begin{array}{l}\text { No of } \\
\text { patients }\end{array}$ & $\begin{array}{l}\text { No }(\%) \\
\text { of deaths }\end{array}$ & $\begin{array}{l}70 \% \\
\text { Confidence } \\
\text { limits }\end{array}$ \\
\hline $\begin{array}{l}\text { Persistent ductus arteriosus } \\
\text { (PDA) }\end{array}$ & 12 & $3(25)$ & $11-44$ \\
\hline Subaortic stenosis and PDA & 1 & $1(100)$ & \\
\hline Parachute mitral valve (PMV) & 1 & $0(0)$ & \\
\hline Tetralogy of Fallot (TOF) & 1 & $0(0)$ & \\
\hline$P M V$ and TOF & 1 & $0(0)$ & \\
\hline \multicolumn{4}{|l|}{ Multiple ventricular septal } \\
\hline & 1 & $0(0)$ & \\
\hline $\begin{array}{l}\text { Dextrocardia } \\
\text { Subpulmonary stenosis }\end{array}$ & 1 & $0(0)$ & \\
\hline & 1 & $\begin{array}{l}0(100) \\
0(0)\end{array}$ & \\
\hline Double mitral orifice (DMO) & 5 & $1(20)$ & $3-53$ \\
\hline DMO and aortic coarctation & 1 & $0(0)$ & \\
\hline Unroofed coronary sinus & 2 & $0(0)$ & \\
\hline \multicolumn{4}{|l|}{ Previous pulmonary artery } \\
\hline banding & 2 & $1(50)$ & $7-93$ \\
\hline Total & 30 & $8(27)$ & $18-37$ \\
\hline
\end{tabular}

monary bypass technique with moderate to severe hypothermia (mean $22^{\circ} \mathrm{C}$ range $15-35^{\circ} \mathrm{C}$ ) and low flow. A single period of aortic cross clamping and cold potassium cardioplegia, which we adopted in 1978, were used. The mean (SD) ischaemic time was 73 (60) minutes. The lesion was approached through a longitudinal right atriotomy, and the competence of the valve was assessed before and after repair by injecting cold saline solution under pressure into the ventricles.

In this surgical series two different techniques were used to repair the malformed left atrioventricular valve. For many years we have followed the most traditional approach, which aims at reconstructing a "normal" two leaflet mitral valve. Nevertheless, since 1980 we have reconstructed the left atrioventricular valve as a three leaflet valve and applied techniques to preserve its natural" configuration and function.

Before 1980 all the partial forms $(n=21)$, including one case with a competent valve, were repaired using the conventional technique of partial or complete suture of the cleft with interrupted 5/0 Dacron sutures to form a two leaflet valve. After 1980, 17 patients were treated with this technique, whereas in 19 the mitral incompetence was corrected by annular plication, resection of secondary chordae, and preservation of the three leaflet configuration. In the latter cases a pericardial patch was routinely sutured to the valvar annulus, and the suture line passed to the left side of the atrioventricular junction in order to leave the atrioventricular node and the coronary sinus on the right side. Intermediate forms were treated as partial atrioventricular septal defects after repair of the small ventricular septal defect(s) through the right atrioventricular orifice. In seven of these cases the cleft was completely sutured to obtain a two leaflet valve.

Before 1980 complete forms were repaired with a technique similar to that described by Rastelli in 1968 $(\mathrm{n}=17) .{ }^{7}$ The bridging leaflets were divided and a pericardial patch was sutured to the ventricular septum. A two leaflet valve was reconstructed on the left side by suturing together the divided anterior and posterior components of the bridging leaflets and was secured to the pericardial patch on the mural side. After 1980 this technique was used in 10 patients. After April 1981 we adopted a two patch technique $(n=14)$, as initially proposed by Carpentier, ${ }^{8}$ which results in a competent three leaflet valve. A septal commissure is reconstructed on top of a Dacron patch, which is carefully tailored to fit the anterior and posterior bridging leaflets. In two cases a combination of both techniques was used.

\section{STATISTICAL ANALYSIS}

The influence of demographic, anatomical, clinical, and operative variables was studied in relation to the operative mortality (death in hospital or within $\mathbf{3 0}$ 

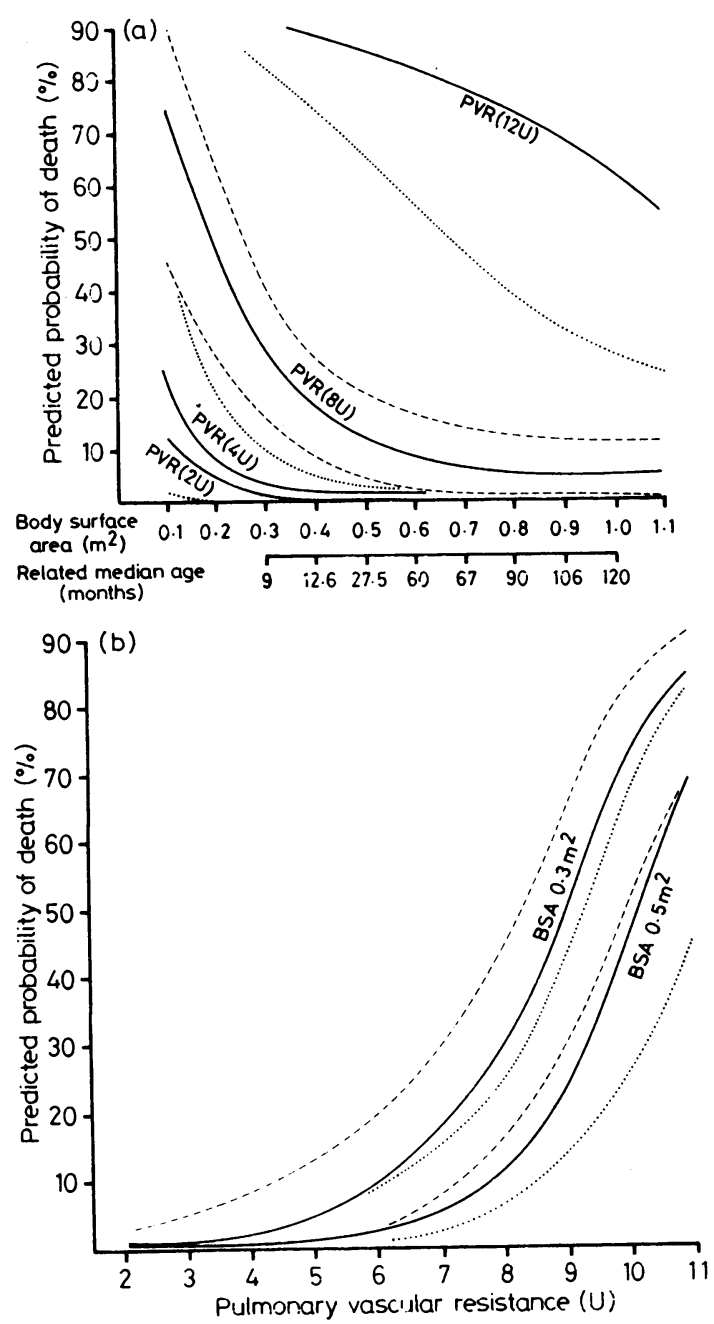

Fig. 1 Nomograms of the predicted probability of death obtained from the equation in Table 4, according to (a) the size of the patient $\left(B S A\left(m^{2}\right)\right)$ and $(b)$ the degree of pulmonary vascular resistance (PVR $(U))$ in patients with absent left ventricular dominance, who underwent successful primary repair (three leaflet technique) of the left atrioventricular valve. (a) For simplicity only the lower $70 \%$ confidence limit of the $12 \mathrm{U}$ curve, the upper $70 \%$ confidence limit of the $4 U(P V R)$ curve, and the lower $70 \%$ confidence limit of the $2 U$ curve (dotted lines) have been included; the dashed lines represent the upper and lower confidence limits of the $8 U$ curve. (b) The curves for a patient's size of 0.3 and $0.5 \mathrm{~m}^{2}(B S A)$ are shown. Dotted lines represent the $70 \%$ confidence limits of the lower curve and dashed lines the $70 \%$ confidence limit of the upper curve.

days of operation) and to severe malfunction of the valve repair.

Simple univariate and multivariate techniques were used. The proportions of operative deaths were tabulated as percentages with their $70 \%$ confidence limits.

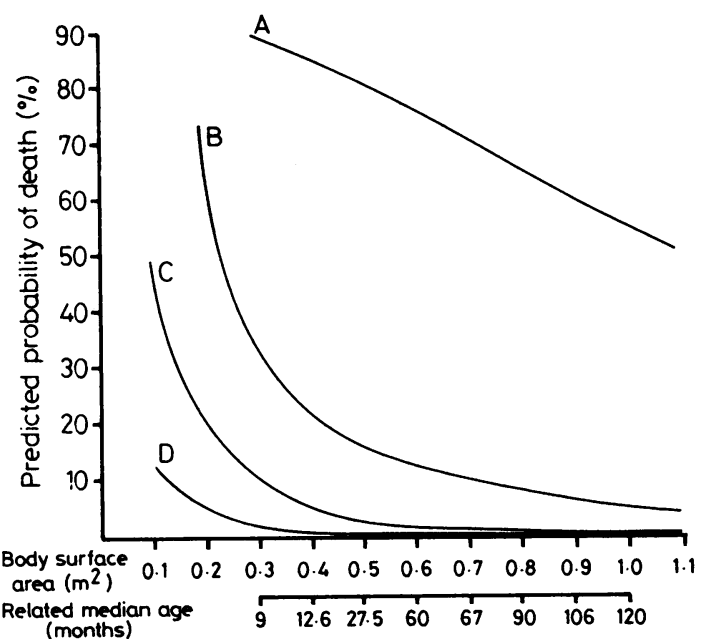

(months)

Fig. 2 Nomograms of the predicted probability of death, obtained from the equation in Table 4, for patients with normal pulmonary vascular resistance $(2 \mathrm{U})$ according to the body size (BSA) and to several combinations of the incremental risk factors: $A$, valve repair failure, two leaflet technique, and no left dominance; $B$, left dominance and three leaflet technique; $C$, two leaflet technique, no left dominance, no valve repair failure; $D$, three leaflet technique, no left dominance, no valve repair failure.

The influence of categorical variables was tested by Pearson's $\chi^{2}$ statistic. Medians and means were calculated for the continuous variables, and $t$ tests with a separate estimate for equal and unequal variances were performed. Multivariate analysis was carried out as described ${ }^{9}$ by the non-linear logistic regression model. The logistic coefficients are given with their standard deviation, and the nomograms (Figs. 1 and 2) derived from the logistic equation include their $70 \%$ confidence limits. All the p values are two tailed tests for differences. Those $<0.2$ are considered posibly significant and those $<0.1$ as probably significant.

\section{Results}

\section{MORTALITY}

Twenty of the 111 patients died, giving an operative mortality of $18 \%(14-23 \%)$. Two further patients died in hospital 37 and 39 days after the operation. Both had complete forms of atrioventricular septal defect. The first of these two patients was discharged after an uneventful recovery but returned later for minor surgery for a dehiscent wound. He was artificially ventilated and suffered oil contamination of the lungs from faulty equipment, which led to giant cell pneumonia. The second patient was an infant with severe cachexia that proved irreversible despite good operative results. He developed a salmonella infec- 
tion, which was managed with intravenous hyperalimentation that resulted in a candida septicaemia. These two patients were therefore considered alive in our analysis of operative deaths.

The mode of death in 17 patients (cases 2-18) was low output syndrome (Table 2). Six patients died during surgery and 11 in the intensive care unit. The first six patients could not be weaned from the cardiopulmonary bypass. In all of them total bypass was reinstituted and a second attempt to improve valvar function carried out. One patient received a Lillehei-Kaster prosthesis. At necropsy, one patient was found to have an undiagnosed subaortic stenosis and one severe right ventricular hypoplasia.

Of the 11 patients who died in the intensive care unit, five had an unsatisfactory valve repair. Of these five, two had severe stenosis (Table 2). One patient (case 1) developed an inferior myocardial infarction, one (case 8) had partial dehiscence of the pericardial patch from the ventricular septum, and one (case 7) right ventricular hypoplasia with a stenotic tricuspid valve. In five of the remaining six patients the low output syndrome was unrelated to the competence of the valve, which was good. Grade 3 and grade 4 obstructive changes of the pulmonary arteries were found in three of these patients at necropsy. In two patients histological examination of the lungs was not performed; however, pulmonary vascular resistance $(9$ and $11 \mathrm{U}$ ) was increased preoperatively. The cause of death was unclear in the final patient (a 1 month old baby, case 18) but was probably related to prolonged cardiopulmonary bypass ( 80 minutes).

Of the three patients who did not have low output syndrome, one (case 1) with a partial atrioventricular septal defect died suddenly on the third postoperative day of an acute myocardial infarction. One (case 20) died of obstructive laryngeal oedema soon after extubation, and one died after 43 days because of pro-

Table 2 Details of 20 patients who died after repair of atrioventricular septal defects (1975-82).

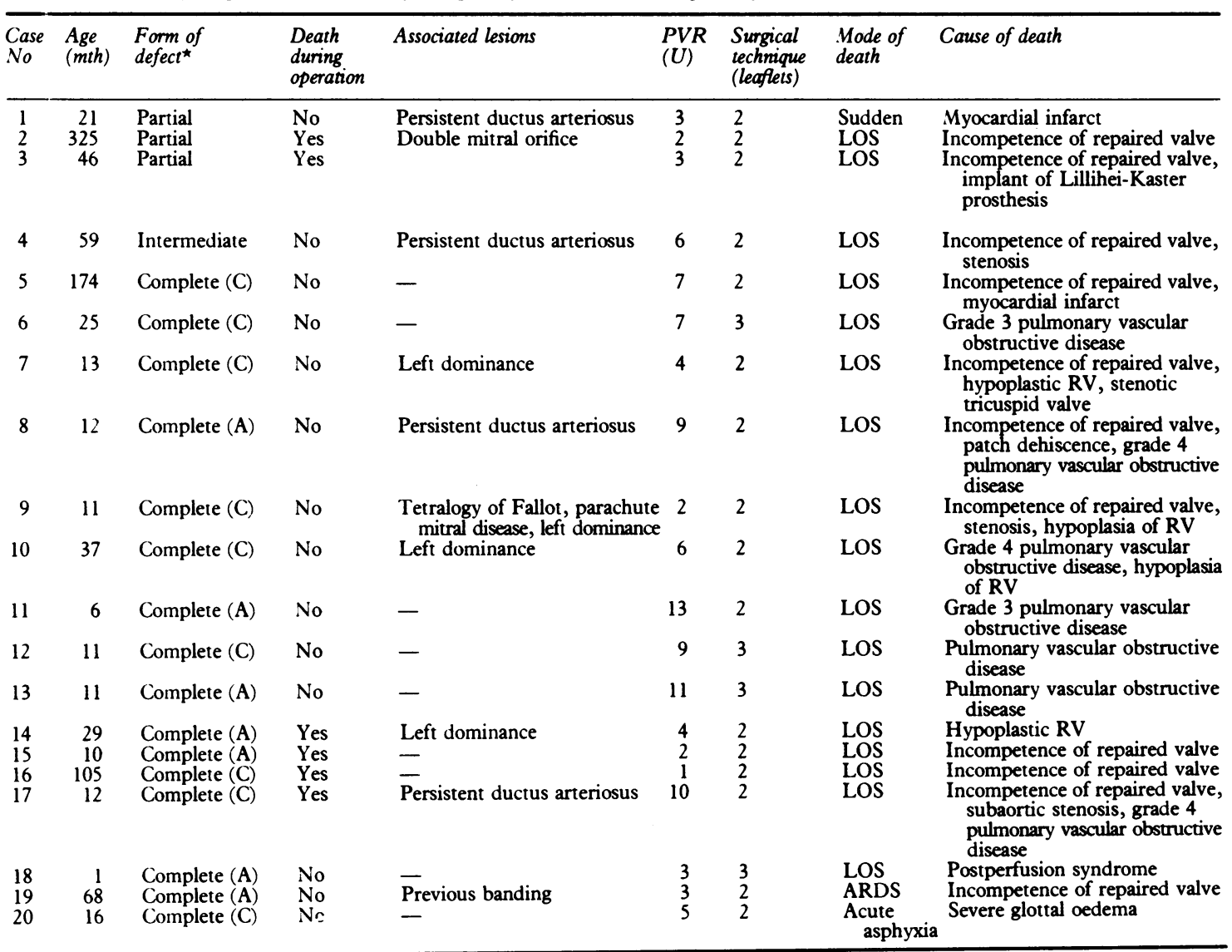

PVR, pulmonary vascular resistance; LOS, low output syndrome; ARDS, acute respiratory distress syndrome; RV, right ventricle. $\star A, B, C$ denotes type of anterior bridging leaflet morphology (Rastelli). 
longed mechanical ventilation for respiratory failure. tive mortality of those with the intermediate form (1/

UNIVARIATE ANALYSIS

Partial and intermediate forms

11) was $9 \cdot 1 \%(1 \cdot 2-28 \%)$ and of those with the partial form $(3 / 57) 5.9 \%(3.0-11 \%)$ (NS). For statistical convenience these two forms are grouped together since Four patients in this group died (Table 3). The opera- after separate closure of the small ventricular septal

Table 3 Univariate analysis of surgical mortality in patients with atrioventricular septal defects (partial, intermediate, complete forms) (1975-82).

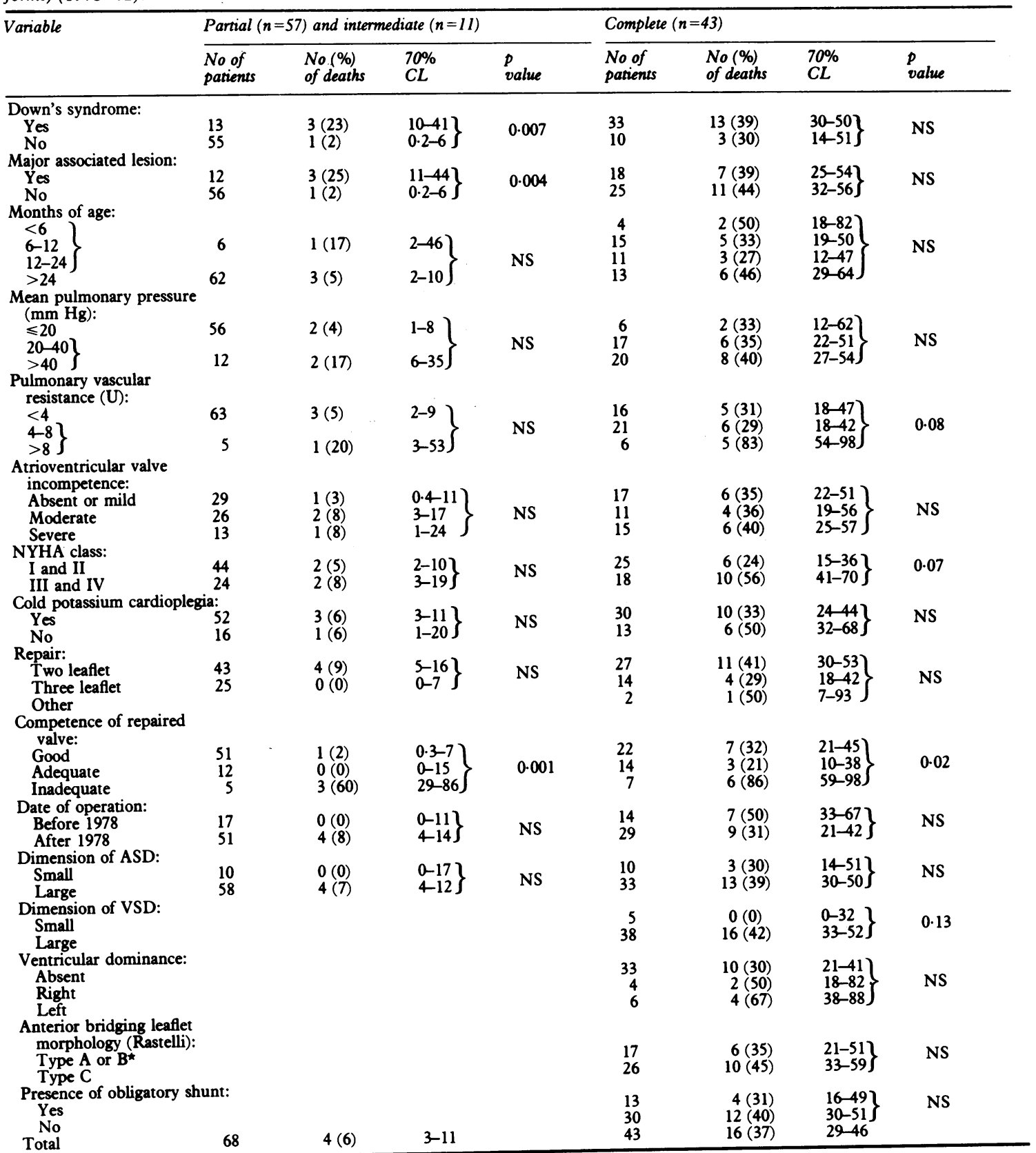

CL, Confidence limits; ASD, atrial septal defect; VSD, ventricular septal defect. ${ }^{\star}$ Two patients. 
$\operatorname{defect}(s)$ intermediate forms were treated as partial forms.

The mortality rate was significantly higher in the patients with Down's syndrome (23\%) and in those with associated anomalies (25\%) than in genetically normal patients $(2 \%)(p=0.007$ and 0.004$)$. In three fatal cases the repaired left atrioventricular valve was severely incompetent, and this was considered to have an important bearing on the surgical outcome $(p=0.0001)$.

\section{Complete forms}

Sixteen out of 43 patients died, giving a mortality rate of $37.2 \%(29-46 \%)$ (Table 3$)$. Mortality was significantly related to the result of the valve repair, rising to $86 \%$ in cases of severely incompetent valves $(p=0.02)$. Mortality was also probably related to pulmonary vascular resistance: it was $30 \%$ if the resistance was mildly $(4 \mathrm{U})$ or moderately $(\leqslant 8 \mathrm{U}$ ) increased but $83 \%$ if it was greatly increased $(>8 \mathrm{U})$. Failures were probably also related to the clinical functional status $(p=0.007)$. The large size of the ventricular septal defect was also possibly responsible $(p=0.13)$ for an increased risk.

\section{MULTIVARIATE ANALYSIS}

This analysis was performed in the total group of 111 patients (Table 4). It failed to show any significant independent incremental risk effect of Down's syndrome, functional class, severity of preoperative valvar incompetence, type of canal, morphology of the anterior leaflet (Rastelli), major associated lesions, size of the ostium primum or ventricular septal defect, mean pulmonary pressure, presence of obligatory shunt, operative date, type of myocardial protection, and duration of the ischaemic time $(p>0.2)$.

Significant incremental risk factors were the small size of the patient $(p=0.05)$, pulmonary vascular resistance $(p=0.003)$, expressed as their quadratic polynomial term, left ventricular dominance $(p=0.004)$, and the failure to obtain (initially) a competent repair of the valve $(p=0.0001)$. The operative technique of repair was probably also significant $(p=0.09)$. In fact, the risk was increased when we attempted to repair the incompetent left atrioventricular valve using the two leaflet technique (dividing and suturing together the bridging leaflets in the complete form or suturing completely the cleft in the partial and intermediate forms). This approach resulted in a statistically significant increase in the number of unsatisfactory valve repairs with haemodynamically important residual incompetence or stenosis $(p=0.05)$, as shown by the results of the multivariate analysis of valve repair failure (Table 5 ). This outcome was most likely in the intermediate $(p=0.03)$ and in the complete $(p=0.05)$ forms of atrioventricu-
Table 4 Multivariate analysis of surgical mortality in 111 patients with atrioventricular septal defects (partial, intermediate, and complete forms) (1975-82).

\begin{tabular}{llll}
\hline Veriable & Logit units & $S D$ & $p$ value \\
\hline Intercept & -6.32 & 1.65 & 0.0001 \\
$\begin{array}{l}\text { Natural logarithm of BSA }\left(\mathrm{m}^{2}\right) \\
\text { Failure of primary }\end{array}$ & -1.92 & 0.97 & 0.05 \\
$\begin{array}{l}\text { valve repair } \\
\text { Left ventricular dominance }\end{array}$ & 4.70 & 1.16 & 0.0001 \\
$\begin{array}{l}\text { Square of pulmonary vascular } \\
\text { resistance }(\mathrm{U})\end{array}$ & 0.048 & 0.01 & 0.0030 \\
$\begin{array}{l}\text { Two leaflet left valve } \\
\text { reconstruction }\end{array}$ & 1.72 & 1.01 & 0.09 \\
\hline
\end{tabular}

Table 5 Multivariate analysis of failure of the valvar repair $(n=12)$ in 111 patients with atrioventricular septal defects (1975-82).

\begin{tabular}{|c|c|c|c|}
\hline Variable & Logit units & $S D$ & p value \\
\hline Intercept & -5.59 & 1.34 & 0.00003 \\
\hline $\begin{array}{l}\text { Atrioventricular septal defect: } \\
\text { Intermediate } \\
\text { Complete }\end{array}$ & $\begin{array}{l}2.31 \\
1.66\end{array}$ & $\begin{array}{l}1.08 \\
0.85\end{array}$ & $\begin{array}{l}0.03 \\
0.05\end{array}$ \\
\hline $\begin{array}{l}\text { Degree of preoperative valvar } \\
\text { incompetence }(0-3)\end{array}$ & 0.56 & 0.38 & 0.14 \\
\hline $\begin{array}{l}\text { Two leaflet left valve } \\
\text { reconstruction }\end{array}$ & 1.63 & 0.85 & 0.05 \\
\hline
\end{tabular}

lar septal defect and was possibly related to preoperative incompetence of the left atrioventricular valve $(\mathrm{p}=0 \cdot 14)$.

\section{Discussion}

In the surgical treatment of atrioventricular septal defects it is essential to restore adequate competence of the left atrioventricular valve, thus minimising the occurrence of severe low output syndrome, which in this series was the principal mode of death.

The achievement of a competent valve repair is most critical in very young patients, who are more frequently affected by concomitant lesions, ${ }^{10}$ hypoplasia of one ventricle, ${ }^{4}$ congestive heart failure, and increased pulmonary vascular resistance. ${ }^{11}$ Furthermore, the damaging effect of the extracorporeal circulation is usually more pronounced in these patients. ${ }^{12}$ Important progress was made when we modified our original policy of reconstructing a two leaflet left atrioventricular valve and adopted the three leaflet technique and the two patch technique. This method avoids distortion of the valve mechanism while effectively counteracting regurgitation through the valve. This approach resulted in a lower incidence of severe postoperative valvar dysfunction (Fig. 3), although firm conclusions cannot yet be drawn because of the broad confidence limits. We are, however, convinced that in creating a two leaflet left atrioventricular valve the extensive remodelling techniques increase the risk of aggravating the original incompetence. As our 


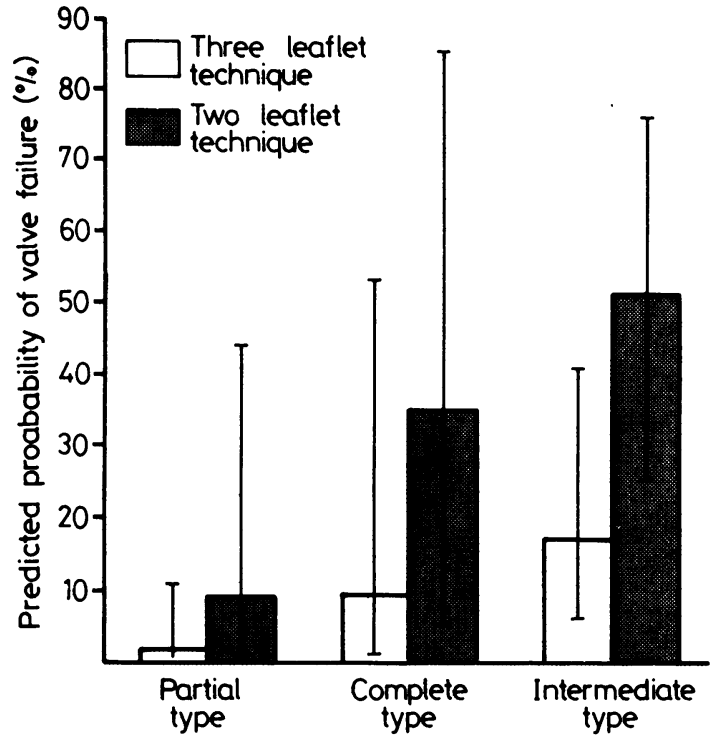

Fig. 3 Predicted probabilities of valve repair failure obtained from the equation in Table 5 for patients having severe $(3+)$ preoperative valvar incompetence according to the type of atrioventricular septal defect and to the technique of repair. Bars represent $70 \%$ confidence limits.

experience increases we are confident that a competent valve repair may be achieved in most cases, irrespective of the morphology of the valvar tissue and of the related septal structures.

The morphology of the leaflets and the size of the septal defect are in fact intimately related to the clinical presentation and to the natural history of the disease, but in our analysis they do not seem to have influenced by themselves the risk of surgical repair. This risk is indeed related to the size of the patient and to the level of pulmonary vascular resistance.

Several studies report excellent results of repair in infancy, and we agree that an early and complete repair of valvar dysfunction may give good results. ${ }^{13} 14$ Nevertheless, our efforts have often been frustrated by the number of patients with some degree of ventricular dominance (10 cases) and by the presence of early and severe grade 3 and 4 pulmonary vascular obstructive changes (four cases confirmed at necropsy). ${ }^{4}$ With the recent technical inprovements the risk of surgery may be predicted to be almost nil in patients with normal or moderately increased vascular resistance and absent ventricular dominance who require surgery later in life (mostly partial forms of atrioventricular septal defect) (Fig. 1a).

The risk increases in patients who require surgery in infancy (mostly those with the complete and intermediate forms). The small size of the patient complicates the technical execution of a satisfactory repair because the morphological details of the valve are more difficult to identify and the tissues are more fragile and immature so that even a single stitch, inappropriately positioned, may seriously distort the valvar geometry. Because of their small size these patients are particularly vulnerable to prolonged cardiopulmonary bypass. Thus in patients with increased pulmonary vascular resistance ( $\geqslant 8 \mathrm{U}$ ) the risk effect of small size is significantly increased (nonoverlapping confidence bands) (Fig. 1a). A similar finding was recently reported by Abruzzese. ${ }^{15}$

Despite the fact that our crude mortality rate may appear high, our analysis shows that our results compare favourably with the most successful reported. ${ }^{14}$ In the absence of ventricular dominance and with the recent technical improvements we found (Fig. 1b) a mortality rate consistently $<10 \%$ in infants with a body surface area of $0.3 \mathrm{~m}^{2}$ (corresponding to a median age of 9 months) and pulmonary vascular resistance of $\leqslant 6 \mathrm{U}$ ( $70 \%$ confidence limits $2-18 \%)$. The same result was achieved in children with a body surface area of $0.5 \mathrm{~m}^{2}$ (median age 27.5 months) and pulmonary resistance $\leqslant 8 \mathrm{U}$ ( $70 \%$ confidence limits $5-24 \%)$. In very small infants (aged 6 months) pulmonary artery banding may be an alternative to primary surgical correction. ${ }^{16}$ We carried out a repair in four infants $<6$ months of age, two of whom died, one as a result of pulmonary vascular obstructive disease. Our experience in this field is therefore limited.

If it is assumed that a body surface area of $0.2 \mathrm{~m}^{2}$ is the lowest possible value for the infants (with a mean weight of $3.6 \mathrm{~kg}$ ) reported by Silverman et al ${ }^{16}$ and that most of their patients had moderately increased pulmonary resistance $(4 \mathrm{U})$ our parametric analysis of primary correction indicates a mortality of $8 \%(0.05-$ $21 \%)$. This mortality is comparable to the $6 \%(0-19 \%)$ (one death/17 patients) mortality with banding. ${ }^{16}$ On the other hand, if pulmonary vascular resistance is greatly increased the results of banding are unpredictable.

Our group has found that the level of pulmonary vascular resistance correlates well with that of pulmonary obstructive changes. ${ }^{4}$ Nevertheless, if resistance (measured at cardiać catheterisation) falls to normal or moderately increased values (with $100 \% \mathrm{FIO}_{2}$ ) bronchoarteriolar spasm may be avoided, with careful hyperventilation and alkalosis, and the patient may recover uneventfully.

In this series associated lesions did not appear to be a significant incremental risk factor. Double mitral orifice was eliminated by our valvar repairs so that only one of the six patients with this feature died. One patient with two associated major lesions-tetralogy of Fallot and parachute deformity of the mitral valve-also died. Two patients, each with one of the above lesions, survived. When undiagnosed a sub- 
aortic discrete stenosis is fatal, as shown in one patient in our series.

Left ventricular dominance was a highly significant risk factor (Fig. 2). Furthermore, two of four patients with right ventricular dominance died. Both these conditions have been recognised as being particularly unfavourable ${ }^{14} 17$ since they usually indicate a particular malformed valve with malalignment of the chordal structures and thus a more difficult repair. Furthermore, a hypoplastic right ventricle may be more susceptible to failure in a patient with high postoperative pulmonary vascular resistance, whereas a hypoplastic left ventricle may be unable to sustain the systemic circulation. Recognition of hypoplastic left ventricle is possible with the use of axial views and cross sectional echocardiography and should raise the question of the feasibility of primary repair.

Iatrogenic block was not seen in this series. This complication is entirely avoidable since the surgical anatomy of the conduction tissue is well documented. ${ }^{18}$

We thank Professor Gaetano Thiene, who examined the anatomical material, and Dr Ennio Segato (Centro di Calcolo dell'Università di Padova), who assisted us in the statistical computations.

This work was supported by a grant from the Consiglio Nazionale delle ricerche, Rome, Italy.

\section{References}

1 Bharati S, Lev $M$. The spectrum of common atrioventricular orifice (canal). Am Heart $\mathcal{f}$ 1973; 86: 553-61.

2 Bharati S, Lev M, McAllister HA Jr, Kirklin JW. Surgical anatomy of the atrioventricular valve in the intermediate type of common atrioventricular orifice. $\mathcal{f}$ Thorac Cardiovasc Surg 1980; 79: 884-9.

3 Somerville J. Atrioventricular canal malformation. In: Anderson RH, Shinebourne EA, eds. Pediatric cardiology 1977. London: Churchill Livingstone, 1978: 417-28.

4 Thiene G, Mazzucco A, Grisolia EF, et al. Postoperative pathology of complete atrioventricular defects. $\mathcal{F}$ Thorac Cardiovasc Surg 1982; 83: 891-900.

5 Berger TJ, Blackstone EH, Kirklin JW, Bargeron LM
Jr, Hazelrig JB, Turner ME Jr. Survival and probability of cure without and with operation in complete atrioventricular canal. Ann Thorac Surg 1979; 27: 104-11.

6 Pacifico AD, McKay R. Advances in the surgical management of congenital heart disease in infants and children. Cardiovasc Clin 1981; 12: 127-41.

7 Rastelli GC, Ongley PA, Kirklin JW, McGoon DC. Surgical repair of the complete form of persistent common atrioventricular canal. $\mathcal{f}$ Thorac Cardiovasc Surg 1968; 55: 299-308.

8 Carpentier A. Surgical anatomy and management of the mitral components of atrioventricular canal defects. In: Anderson RH, Shinebourne EA, eds. Pediatric cardiology 1977. London: Churchill Livingstone, 1978: 477-90.

9 Rizzoli G, Rubino M, Mazzucco A, et al. Progress in the surgical treatment of ventricular septal defect: an analysis of twelve years' experience. Thorac Cardiovasc Surgeon 1983; 31: 382-8.

10 Ugarte M, Enriquez De Salamanca FE, Quero M. Endocardial cushion defects: an anatomical study of 54 specimens. Br Heart $\mathcal{f}$ 1976; 38: 674-82.

11 Newfeld EA, Sher M, Paul MH, Nikaidoh H. Pulmonary vascular disease in complete atrioventricular canal defect. Am f Cardiol 1977; 39: 721-6.

12 Kirklin JW. A letter to Helen. $\mathcal{F}$ Thorac Cardiovasc Surg 1979: 78: 643-54.

13 Studer M, Blackstone EH, Kirklin JW, et al. Determinants of early and late results of repair of atrioventricular septal (canal) defects. F Thorac Cardiovasc Surg 1982; 84: $523-42$.

14 Bender HW Jr, Hammon JW Jr, Hubbard SG, Muirhead J, Graham TP. Repair of atrioventricular canal malformation in the first year of life. $\mathcal{F}$ Thorac Cardiovasc Surg 1982; 84: 515-22.

15 Abruzzese PA, Livermore J, Sunderland $\mathrm{CO}$, et al. Mitral repair in complete atrioventricular canal: ease of correction in early infancy. $\mathcal{F}$ Thorac Cardiovasc Surg 1983; 85: 388-95.

16 Silverman N, Levitsky S, Fisher E, DuBrow I, Hastreiter A, Scagliotti D. Efficacy of pulmonary artery banding in infants with complete atrioventricular canal. Circulation 1983; 68 (supp II): 148-53.

17 Ilbawi MN, Idriss FS, De Leon SY, et al. Unusual mitral valve abnormalities complicating surgical repair of endocardial cushion defects. $\mathcal{F}$ Thorac Cardiovasc Surg 1983; 85: 697-704.

18 Thiene G, Wenink ACG, Frescura C, et al. Surgical anatomy and pathology of the conduction tissues in atrioventricular defects. F Thorac Cardiovasc Surg 1981; 82: 928-37. 